\title{
NEW TEACHING STRATEGIES IN THE TEACHING OF THE ARCHITECTURAL PROJECT
}

\author{
M.I. Alba Dorado \\ University of Málaga (SPAIN) \\ maribelalba@uma.es
}

\begin{abstract}
Today we will observe the need to rethink the teaching and learning models at Schools of Architecture, reconsidering the ways of teaching and learning, attending not only to what we want to teach, but also to how we are going to teach with the objective of moving from the traditional model of transmission of knowledge from the teacher to the student, to a model based on the development of competences in the student.
\end{abstract}

In this sense, the teaching of architectural design should step away from the attitude that is still prevalent in many schools, consisting of conveying predetermined teaching or a closed and complete architectural culture, which attempts to exhaust all the avenues of knowledge, showing a strict and infallible method. What is needed, though, is an active and plural education that considers the complexity of architecture, based on ongoing research and part of an open, flexible and dynamic disciplinary discourse. An education that allows students to develop skills and generate new knowledge from the creation of learning situations which stimulate independent learning, facilitate subsequent ongoing training and enable a more critical and profound intellectual development. Undoubtedly, students must acquire lots of knowledge and skills, and there are many learning processes which must be simultaneously present of their training.

In this sense, this paper aims to define a series of teaching strategies that aim to establish a teaching of Architecture oriented more to show an attitude towards the project, to encourage, stimulate and involve students in their own process of learning, helping them to develop their capacity to learn to learn. A training oriented more than the pursuit of results to focus on the processes that lead to them. A teaching focused more on teaching an attitude, a disposition towards the project, in generating learning situations that have as their objective the training of the student rather than the accumulation of objective knowledge. In short, a teaching capable of defining more flexible learning pathways, which support ongoing training from the earliest stages and in which training on information prevails with the aim of creating learning situations that facilitate further training and enable a more critical and deep intellectual development that enables to generate knowledge.

Keywords: Teaching strategies, architectural project, innovation, teaching, learning. 